\title{
Integração ensino-serviço-comunidade: concepções atribuídas pelos estudantes de enfermagem
}

\section{Teaching-service-community integration: conceptions allocated by nursing students}

\author{
Camila Dalcól ${ }^{1}$, Elias Pedro da Silva Junior ${ }^{2}$, Mara Lúcia Garanhani ${ }^{3}$, Marli \\ Terezinha Oliveira Vannuchi ${ }^{4}$, Elisabete Fátima Pólo de Almeida Nunes ${ }^{5}$
}

\section{Resumo}

\begin{abstract}
O objetivo deste estudo foi analisar as concepções de integração ensino-serviço-comunidade atribuídas pelos estudantes de enfermagem. Trata-se de um estudo exploratório, compreensivo, de abordagem qualitativa, do tipo estudo de caso, realizado em um curso de graduação em enfermagem de uma universidade do norte do Paraná. A coleta de dados ocorreu em outubro de 2014 e agosto de 2015, por meio de grupos focais, envolvendo 37 estudantes. Os grupos focais foram gravados, transcritos na íntegra e submetidos à análise de conteúdo de Bardin. A pesquisa foi aprovada pelo Comitê de Ética da universidade em estudo com CAAE $n^{\circ} 18931613.5 .0000 .5231$. Das concepções de integração ensinoserviço-comunidade descritas pelos estudantes emergiram quatro categorias: concepções sobre o ensino; avançando para a integração ensino-serviço; integrando o ensino e a comunidade; e compreendendo a integração ensino-serviço-comunidade. As concepções sobre ensino-serviço e comunidade envolveram a integração entre diferentes cursos da área da saúde, o primeiro contato com o serviço e profissionais de saúde, o trabalho em equipe multiprofissional, a compreensão do ser humano como um todo, bem como a relação entre teoria e prática nos diferentes níveis de atenção. Os resultados foram discutidos de acordo com o pensamento complexo de Edgar Morin. Ressaltamos a importância da integração ensinoserviço-comunidade na formação do enfermeiro em um processo compartilhado entre instituições de ensino, enfermeiros e demais profissionais da área da saúde, bem como com a comunidade.
\end{abstract}

Palavras-Chave: Ensino. Serviço. Comunidade. Enfermagem. Currículo.

\begin{abstract}
The purpose of this study was to analyze the conceptions of teaching-service-community integration attributed by nursing students. This is an exploratory, comprehensive, qualitative, case-study-based study conducted in a nursing undergraduate course at a university in the north of Paraná. Data collection took place in October 2014 and August 2015, through focus groups, involving 37 students. The focus groups were recorded, transcribed in full and submitted to Bardin content analysis. The research was
\end{abstract}

\footnotetext{
1 Mestre em Enfermagem pela Universidade Estadual de Londrina, Londrina, Paraná, Brasil. Docente na Universidade Estadual do Norte do Paraná, Luiz Meneghel, Paraná, Brasil. E-mail: kamila_dalcol@hotmail.com

2 Mestrando pela Universidade Estadual de Londrina, Londrina, Paraná, Brasil. Docente do Departamento de Enfermagem do Centro Universitário Filadélfia, Londrina, Paraná, Brasil.

3 Doutorado em Enfermagem pela Universidade de São Paulo, Ribeirão Preto, São Paulo, Brasil. Professora Associada do Departamento de Enfermagem da Universidade Estadual de Londrina, Londrina, Paraná, Brasil.

4 Doutorado em Saúde Pública pela Universidade de São Paulo, São Paulo, São Paulo, Brasil. Professora Associada do Departamento de Enfermagem da Universidade Estadual de Londrina, Londrina, Paraná, Brasil.

5 Doutorado em Saúde Coletiva pela Universidade Estadual de Campinas, Campinas, São Paulo, Brasil. Professora do Departamento de Saúde Coletiva da Universidade Estadual de Londrina, Londrina, Paraná, Brasil.
} 
approved by the Ethics Committee of the university under study with CAAE $\mathrm{n}^{\circ}$ 18931613.5.0000.5231. From the conceptions of teaching-service-community integration described by the students emerged four categories: conceptions about teaching; advancing towards teaching-service integration; integrating teaching and community; and understanding teaching-service-community integration. The conceptions about teaching-service and community involved the integration between different courses in the health area, the first contact with the service and health professionals, the multiprofissional teamwork, the understanding of the human being as a whole, as well as the relation between theory and practice at different levels of attention. The results were discussed according to Edgar Morin's complex thought. We emphasize the importance of the teaching-service-community Integration in the training of nurses in a process shared between educational institutions, nurses and other professionals in the health area, as well as with the community.

Keywords: Education. Service. Community. Nursing. Curriculum.

\section{Introdução}

A formação profissional do Enfermeiro vem se transformando por meio de sucessivas mudanças curriculares, a partir de amplas discussões de novas propostas pedagógicas, com o intuito de formar profissionais que atendam às necessidades reais e atuais dos serviços de saúde e da comunidade. ${ }^{(1-2)}$ As instituições de ensino devem estar envolvidas com a formação de profissionais críticos, reflexivos, éticos e políticos, impulsionando a profissão e repercutindo positivamente na formação de enfermeiros, lançando mão de uma maior integração ensino-serviço-comunidade (IESC). ${ }^{(1)}$

As propostas de articulações entre o ensino, serviços de saúde e a comunidade no processo de formação profissional é antiga e tendo sido motivo de variadas experimentações, algumas das quais resultaram em avanços ao longo das últimas décadas no Brasil. Essa articulação vem sendo enfatizada pelo Ministério da Saúde como uma estratégia importante para a formação de profissionais que atendam aos princípios e diretrizes do Sistema Único de Saúde (SUS). ${ }^{(3)}$

A IESC pode ser conceituada como a articulação entre os centros formadores de graduação e pósgraduação com os serviços de saúde nos diversos níveis de atenção e esferas governamentais e a participação social nesse processo. ${ }^{(4)}$ Nesta definição, $\mathrm{a}$ articulação diz respeito às relações estabelecidas entre estudantes, professores, trabalhadores dos serviços de saúde e comunidade, organizando-se entre si, promovendo a construção de espaços para a reflexão acerca da própria IESC.

No processo de construção e formação do futuro enfermeiro, os conceitos de ensino, serviço e comunidade, bem como o entendimento de integração destes elementos, torna-se um desafio a ser superado e um objetivo a ser alcançado pelas instituições de ensino, a fim de preparar o profissional de enfermagem para atuar no contexto da saúde de forma a promover a integração ensinoserviço-comunidade.

Referindo-se à complexidade dos desafios a serem superados pelas instituições de ensino, destacamos Edgar Morin, considerado um dos maiores pensadores dos séculos XX e XXI no que se refere à educação, que propõem a teoria do pensamento complexo. Este pensamento retrata "aquilo que é tecido junto", refletindo sua complexidade quando os componentes que constituem um todo são inseparáveis, existindo um tecido interdependente, interativo e inter-retroativo entre as partes e o todo, e entre o todo e as partes, como é o caso da IESC. ${ }^{(5)}$

Diante do exposto, consolida-se a questão orientadora desta pesquisa: quais as concepções de integração ensino-serviço-comunidade atribuídas pelos estudantes de enfermagem? Assim, o objetivo deste estudo foi analisar as concepções de integração ensino-serviço-comunidade atribuídas pelos estudantes de enfermagem. 


\section{Método}

Trata-se de um estudo exploratório compreensivo, com abordagem qualitativa, do tipo estudo de caso. $\mathrm{O}$ estudo foi realizado no curso de Enfermagem de uma instituição de ensino superior situada no norte do Paraná, que oferece 60 vagas anuais, para o ingresso dos candidatos aprovados pelo processo vestibular, sendo em período integral, com duração de quatro anos, no sistema seriado. ${ }^{(6)}$

Optou-se por estudar um curso que utiliza o currículo integrado (CI) há 15 anos como proposta pedagógica, uma vez que adota temas transversais em seu processo de ensino-aprendizagem, sendo a integração ensino-serviço-comunidade um deles. O CI possui sua estrutura em forma de espiral, organizando-se do geral para o específico, de complexidade crescente ao longo do curso, proporcionando sucessivas aproximações entre os temas que se somam e se interligam entre si, totalizando 18 módulos ao longo de quatro anos. Além disso, este currículo caracteriza-se pelo desenvolvimento da aprendizagem crítica reflexiva, da autonomia e da responsabilidade de seus alunos, com a utilização de metodologias ativas. ${ }^{(7)}$

Os temas transversais representam conceitos essenciais para a formação do enfermeiro, devendo ser abordado ao longo dos módulos interdisciplinares, de forma gradativa e de maneira que os alunos compreendam estes temas ao longo dos anos do curso de enfermagem. ${ }^{(8)}$

A fonte de dados dessa pesquisa foi constituída pelos estudantes que cursavam as quatro séries do curso, no momento da realização do estudo. Os critérios de inclusão foram: estar cursando um dos quatro anos do curso; estar devidamente matriculado; aceitar participar da pesquisa livremente, com devida assinatura prévia do termo de consentimento livre e esclarecido. Foram excluídos os estudantes que realizaram parte do curso em outras instituições de ensino.

Foi realizada a coleta de dados em campo, conduzida mediante quatro grupos focais, sendo realizado um grupo focal por série do curso, totalizando 37 estudantes das quatro séries do curso de graduação em enfermagem, entre os meses de outubro de 2014 a agosto de 2015. Os estudantes das quatro séries foram convidados pessoalmente pelo pesquisador principal, em sala de aula, que apresentou o objetivo do estudo, e posteriormente, foi solicitada uma lista com o nome e número do telefone dos interessados em participar do estudo, com os quais foram confirmados a data e local da realização da pesquisa por meio de mensagens eletrônicas.

Os grupos focais ocorreram no intervalo do horário de almoço dos estudantes, das 12:00 ás 14:00 horas, na própria instituição de ensino em estudo, com duração de uma hora a uma hora e meia, sendo oferecido um lanche para os participantes antes da realização dos grupos. Foram realizados ao todo quatro grupos focais, desenvolvidos em dias diferentes, devido à disponibilidade de cada série do curso de enfermagem e do pesquisador.

A realização dos grupos focais ocorreu em cinco momentos. No primeiro, os participantes foram informados quanto aos objetivos da pesquisa, a audiogravação, o anonimato, e, por fim, assinaram o termo de consentimento livre e esclarecido. No segundo momento, foi solicitado aos estudantes que escrevessem em tarjetas de cartolinas coloridas, palavras que eles associavam com cada termo que compunha a IESC, com o objetivo de favorecer a compreensão do fenômeno na visão do próprio sujeito. Em seguida, as tarjetas foram agrupadas por cor em quatro papeis crafts identificados com cada termo - Integração, Ensino, Serviço, e Comunidade. No quarto momento, foi realizada a leitura dos crafts e, por fim, foi solicitado aos estudantes que debatessem acerca das concepções que atribuíram à IESC, sendo estas atividades mediadas pelo pesquisador principal.

O pesquisador principal desta pesquisa foi coordenador dos grupos focais, contando com a colaboração de duas observadoras e da docente 
orientadora. Os grupos focais foram audiogravados, transcritos na íntegra e submetidos à análise de conteúdo proposta por Bardin ${ }^{(9)}$, seguindo três etapas: pré-análise, exploração do material e o tratamento dos resultados que englobam a codificação e a inferência. Os resultados foram discutidos à luz do referencial teórico do pensamento complexo, tratado por Edgar Morin. ${ }^{(5)}$

Para preservar o anonimato dos entrevistados, foram utilizadas as letras "E" para estudante e "G" para grupo focal seguidas de um número que se refere ao número do aluno e número do encontro (1, 2, 3, 4,). Segue um exemplo de configuração: E4G1: Estudante 4, grupo focal 1.

O estudo contemplou a aprovação do Comitê de Ética em Pesquisa da instituição de ensino à qual está vinculada a autora principal, conforme Resolução 466/12, sendo este estudo vinculado a um projeto de pesquisa maior, sob o título: "Currículo integrado de um curso de Enfermagem: temas transversais e formação profissional". Conforme Resolução 466/12, o estudo contemplou a aprovação do Comitê de Ética em Pesquisa, apresentando CEP/UEL com $n^{\circ} 200 / 2013$, em 15 de novembro de 2013.

\section{Resultados}

Foram realizados quatro grupos focais, um por série do curso, participando 12 estudantes da primeira série, 10 da segunda série, nove da terceira série, e seis da quarta série, totalizando 37 estudantes.

A análise das concepções atribuídas pelos estudantes de enfermagem sobre IESC, discutidas nos grupos focais, permitiu organizar os resultados em quatro categorias: concepções sobre o ensino; avançando para a integração ensinoserviço; integrando o ensino e a comunidade; e compreendendo a integração ensino-serviçocomunidade.
Concepções sobre o Ensino

No que concerne ao ensino, as concepções dos estudantes de enfermagem se referiram à proposta metodológica do currículo integrado, a união entre professores e estudantes, bem como a integração dos cursos de enfermagem e medicina.

De acordo com os discursos, pode-se observar que o método de ensino facilita a construção do aprendizado dos estudantes, oportunizado pela proposta pedagógica do curso que integra aulas teóricas e práticas, metodologias ativas, integração entre as disciplinas, relacionamento entre professores e estudantes, ampliando a visão do aluno, tornando-o responsável pelo seu conhecimento e desenvolvimento.

E3G4 Porque a todo momento e, a partir do momento que a gente entrou lá na academia, para estudar, foi dito para gente que o nosso currículo era integral nada de separação, então todas as etapas que a gente foi estudar, nunca separamos: - vamos estudar só fisiologia de tal coisa...vamos fazer só a parte de exame físico... Não, a gente sempre teve estudo focado num todo junto.

E4G4 vamos supor, cada módulo fragmentado, aulas de farmácia, bioquímica, são todas baseadas no mesmo tema, [...] você aprende a fazer integração ali mesmo na aula, você tem a aula e você vai fazendo integração para depois na prática você exercer essa união do ensino.

E4G4 Mas eu acredito que seja muito importante a prática caminhar junto às aulas expositivas e tutoriais, igual ocorre no nosso processo de aprendizado.

E6G4 Eu vejo assim, [...] eu não conhecia esse tipo de ensino, que ele incentiva o próprio aluno buscar o conhecimento, então o aluno tem que aprender, isso para mim eu vejo que é importante futuramente profissional [...] a gente vai aprendendo e buscando mesmo o ensino. 
E3G4 Bom, eu acho que assim, [...] a gente consegue ter uma visão maior, um foco de visão maior, e união assim do ensino em sala com os professores junto ali falando [...], a gente tem contato praticamente desde o primeiro ano, $e$ eu acho que isso faz a diferença, essa união.

E3G4 [...] dentro do hospital eu acho que isso foi sempre estimulado para você ir buscar e trazer, ai você chega com um problema, com a situação do paciente, o professor instiga, fala assim olha, mas como que isso acontece, afeta que será que outro órgão? Será que outro órgão é afetado? Será que a cirurgia que ele vai fazer pode trazer outras complicações para ele? Então te instiga, [...] você sabe que você tem que ir, aquilo vai voltar, e você vai acabar discutindo o caso.

Além da integração entre as disciplinas, no primeiro e segundo ano do curso de enfermagem ocorre a integração com o curso de medicina, em um módulo interdisciplinar chamado de PIN - Práticas Interdisciplinares e Multiprofissional, desenvolvido a nível primário de atenção à saúde. Esta integração torna-se o primeiro contato do estudante com outros cursos da área da saúde, refletindo a futura realidade profissional e preparando o aluno para o trabalho em equipe multiprofissional. Esta integração entre os cursos foi percebida, ora de forma positiva, e ora de forma negativa, tendo o professor como mediador e corresponsável por esta interação.

E1G2 O do primeiro ano era muito interagido, todo mundo se misturava, medicina $e$ enfermagem e o professor também, o professor dava essa abertura, não tinha isso de "ai meus queridinhos são da med”, essa integração com a gente. Então, acho que o professor ajuda na interação né?

E1G2 Quando foi no segundo ano era muito dividido, começava com sentar. Medicina senta de um lado e enfermagem do outro, trabalho era medicina com medicina e enfermagem com enfermagem. Então não tinha interação nenhuma e o professor também tinha uma postura diferente [...].

E1G4 [...] ficava um pouquinho essa divisão, ficava grupinho de medicina, de enfermagem, trabalhando tudo com o mesmo assunto, com mais objetivo, mas teve uma separação, mas foi muito bom que foi o primeiro contato que a gente teve com a medicina [...].

E3G4 [...] eu peguei um grupo com uma professora que focava muito em medicina [...] para mim não teve beneficio nenhum porque eu não aprendi [...] No trabalho que teve ficou enfermagem com enfermagem e medicina com medicina.

E5G2 [...] o professor fazia mais radical. Sabe, separar mais ainda. Deixava a enfermagem mais inferior, então protegia mais o pessoal da "medicina" sabe [...].

\section{Avançando Para A Integração Ensino-Serviço}

A integração do ensino com o serviço foi percebido no momento que os estudantes entram em contato com os profissionais de saúde pela primeira vez, ficando mais evidente no último ano do curso.

E1G1 - a gente vê integração também quando acrescenta esse serviço, que é quando você tem contato com várias pessoas, estudantes, ter contato com os profissionais [...].

E3G4 [...] no segundo ano que foi quando a gente tinha a participação no trabalho acadêmico, [...] para mim, ter essa integração com eles nesse momento, eu acho assim, que agora no quarto ano que a gente acaba tendo mais contato [...].

Diversos profissionais de saúde foram mencionados como membros da equipe 
multiprofissional, destacando enfermeiros, médicos, fisioterapeutas, técnico de enfermagem, psicólogo, assistência social, promovendo um serviço de saúde integrado que necessita trabalhar em equipe. A partir desta percepção, os estudantes percebem a necessidade de aprender a trabalhar com esta equipe, evidenciando a integração entre o ensino e o serviço.

E2G1 a integração eu acho que integra a medicina com enfermagem, então tem essa questão de trabalhar em equipe e tudo mais.

E3G4 - É um serviço bem integral, por que dai mistura todos os profissionais.

E4G4 Na UBS, a gente tem psicólogo, assistente social, então [...] ali eles fazem parte então da equipe saúde da família, tem todo um acompanhamento, é bem legal.

E4G1 [...] a gente vai aprender a lidar com $o$ técnico, com a enfermeira, com o médico, com o fisioterapeuta, entendeu? A equipe multiprofissional [...].

Para que a integração entre discentes e profissionais da equipe de saúde ocorra de forma eficaz, os discentes apontam habilidades que devem ser desenvolvidas ao longo de sua formação, como o respeito, paciência, aceitação, escuta, reflexão e julgamento próprio.

E7G4 Ai você ter que entrar em um lugar e ter que começar a aceitar e respeitar muito mais a opinião de muitas pessoas mais diferentes do que você, e você ter que ter muita paciência, aceitar escutar as outras pessoas, a refletir e também principalmente acho que você aprende a julgar a si mesmo.

E1G4 No quarto ano, no hospital e no posto a gente vê que os profissionais médicos $e$ estudantes de medicina já têm maior respeito, [...] com enfermagem então a gente vê a diferença do começo do curso, depois no final, tem um respeito mútuo, tanto medicina quanto enfermagem.

Apesar da importância do trabalho em equipe e da consciência no desenvolvimento de habilidades relacionais, os discursos também apontam dificuldades neste processo de integração, tais como a mudança de local de estágio em pequeno espaço de tempo, rotatividade entre as equipes e a hierarquia frente aos membros da equipe e ao professor.

E3G2 A gente passou por pelo menos três equipes, ai tinha que conversar de novo, explicar quem a gente era, o que a gente estava fazendo ali, ver como era o trabalho deles e isso dificulta bastante e também porque querendo ou não é pouco tempo de estagio, então assim, quando você está conseguindo interagir com o ambiente e com as pessoas ai acaba. Então acho que quando você começa a pegar fica bem assim na pratica dai termina.

E3G2 Bastante dificuldade, mas assim, uma dificuldade também que às vezes é que a equipe é diferente, tem dias que a gente ficou no hospital X que eles faziam 12 por 36, então todos os dias a equipe era diferente, todos os dias.

E7G2 - [...] Eu acho que me identifico muito nessa questão e a hierarquia que a gente tem. Então, o aluno está no chão e nunca vai poder chegar ao nivel do técnico de enfermagem que é o dinossauro do setor e está lá há 30 anos fazendo errado e vai continuar fazendo errado e não vai aceitar que você fale, do enfermeiro que está lá formado e concursado você não vai poder discordar dele, porque ele é formado e concursado e do professor que está lá te avaliando, te julgando pelo que você não sabe, por mais que você saiba muito mais das coisas. 


\section{Integrando O Ensino E A Comunidade}

No que se refere à integração com a comunidade, os estudantes percebem o significado de compreender o indivíduo e/ou comunidade como um ser humano que deve ser observados em seus aspectos biológicos, psicológicos, sociais, emocionais e econômicos.

E1G4 [...] Participar da família e tudo, aquilo, [...] para mim foi muito significativo, [...] eu levo isso comigo bastante, aquele momento lá que eu passei.

E4G4 quando eu entrei no curso, que nós entramos no curso, sempre foi, como as meninas disseram, falado a respeito de enxergar o ser humano em todos os seus aspectos social, cultural, e que a forma do curso decorrer faz parte do crescimento mesmo.

E6G1 A integridade emocional.

ElG4 É ver o paciente... Que no hospital chega um paciente da gente e se a gente for primeiro na comunidade a gente entende que aquele paciente mora em um lugar, ele tem uma família, e tudo isso vai influenciar ele ao ser levado para o hospital ou não, dependendo da condição socioeconômica dele, dependendo das condições da relação dele com a família, de onde ele mora, tudo isto vai influenciar até no tratamento, até quando ele sair do hospital, como que vai ser quando ele voltar para casa?

Além disso, as concepções de integração entre ensino e comunidade envolvem a empatia pelo próximo, o respeito à integridade física e emocional, bem como à valorização de crenças, costumes e valores da comunidade, tendo o aluno que se despir de seus preceitos.

E4G2 Acho que uma coisa que entrou na integração é a empatia pelas outras pessoas.
E5G1 você tem que tomar cuidado com a integridade fisica [...] envolve o respeito.

E2G1Porque essa comunidade que está lá tem valores, crenças e costumes, então precisa respeitar.

E7G2 Você ser de um nivel social um pouco maior, saber respeitar e valorizar aquelas pessoas que estão lá, você se despir desses seus preceitos em relação à comunidade e você entender que eles são as mesmas pessoas que você, mas que não teve as mesmas oportunidades porque são pessoas mais carentes.

\section{Compreendendo A Integração Ensino-Serviço- Comunidade}

Os estudantes de enfermagem compreendem que integração entre ensino serviço e comunidade ocorre em diversos níveis de assistência à saúde, desde a Unidade Básica de Saúde à UTI móvel, necessitando do trabalho em equipe, devendo seus membros manter uma boa comunicação e conhecer o serviço onde atuam para intervir da melhor maneira para a comunidade.

E1G1 porque na verdade a integração ensinoserviço-comunidade, eu acredito que ele está em todo o serviço, em todo campo ele precisa estar, se é numa UTI móvel, por exemplo, um enfermeiro avançado, se é na casa, um enfermeiro e um médico, precisa estar em integração [...].

E1G4 Eu acredito que cada serviço tem o seu modo de assistência, [...] mas quando eu estou na atenção básica eu preciso encaminhar um paciente, [...] é sempre uma comunicação, e é muito importante para você ter o conhecimento do que o serviço que você trabalha, da finalidade dele.

E3G4 [...] na UBS tenho toda a equipe, nutricionista, serviço social, tem enfermeiro, 
médico, tem psicólogo, terapeuta, tem toda a equipe, então o que acontece, se a gente tiver assim um caso que chama mais atenção, falar olha isso aqui precisa de tal profissional, então a gente vai conversar com todos os profissionais, todo mundo intervém, conversa sobre o caso, fala sobre o caso, e a gente consegue sentar todo mundo junto discutir aquele paciente.

Os discentes entrevistados citaram exemplos de experiências em que vivenciaram esta IESC, relacionando os conhecimentos teóricos adquiridos e o trabalho em equipe com o objetivo de prestar assistência para as necessidades de saúde da comunidade.

E6G4 Porque o serviço que a gente oferta é melhor, porque a gente consegue integrar a psicologia que a gente está estudando, por causa da saúde mental, a gente consegue oferta diferenciada com as aulas da nutrição. Por exemplo: paciente etilista, a gente dá alternativas de alimentação, para ele não sentir tanta falta ou beber ou de fumar, é estilo de vida, a gente dá atendimento, pergunta, conversa com o médico. Mas já tem uma ideia do que vai passar de fármacos, é muito melhor.

E2G2 [...] fazemos um trabalho que a gente reconheceu na família, é que a gente estava estudando sobre diabetes, hipertensão, só que eu e minha colega, a gente descobriu que ela estava sendo violentada, então é abuso moral e físico. Então, a necessidade que a gente encontrou nela na nossa abordagem foi em cima disso, e daí fugiu da diabetes e da hipertensão, pra gente aquilo que chamou a atenção, porque aquilo era mais grave. Ai as professoras gostaram muito do que a gente fez, porque foi uma intervenção boa no processo de saúde da paciente. Então elas viram que a gente teve uma visão holística, como um todo, que a gente procurou falar com a assistente social, informamos a enfermeira, já passamos o caso para o psicólogo, então assim, a gente olhou assim de uma maneira geral, isso podia estar prejudicando a hipertensão dela pela situação que ela vivia e o diabetes também, porque quando of filho brigava, ele não buscava medicamento para a mãe, então a gente olhou desta forma.

\section{Discussão}

Para discutir as concepções a respeito da IESC, como tema transversal na formação profissional dos estudantes do CI do curso de Enfermagem em estudo, utilizou-se o pensamento complexo de Edgar Morin que fornece subsídios para o entendimento da condição humana e o uso dos operadores da complexidade se adequam ao estudo sobre as percepções dos estudantes. Assim, optouse discorrer sobre as concepções de IESC de acordo com os operadores da complexidade.

Existe complexidade, de fato, quando os componentes que constituem um todo (o econômico, o político, o sociológico, o psicológico, o afetivo, o mitológico, entre outros) são inseparáveis e existe um tecido interdependente, interativo e interretroativo entre as partes e o todo, e entre o todo e as partes. ${ }^{(5)}$

Morin relata que no pensamento complexo existe a necessidade dos operadores da complexidade, que são o dialógico, o recursivo e o hologramático. $\mathrm{O}$ operador dialógico envolve juntar e entrelaçar coisas, que aparentemente estão separadas, porém são complementares. ${ }^{(5)}$ Nas palavras de Morin, o operador recursivo "é um processo em que os produtos e os efeitos são, ao mesmo tempo, causas e produtores daquilo que os produziu" 5. E "o princípio hologramático significa que não apenas a parte está num todo, mas que o todo está inscrito, de certa maneira, na parte". ${ }^{(10)}$

\section{Concepções sobre o Ensino}

As concepções sobre o ensino na percepção dos estudantes de enfermagem abrangeram aspectos relacionados ao método de ensino, ao 
relacionamento professor e estudante, bem como a integração com outro curso da área de saúde.

As falas dos estudantes indicaram que o aprendizado está intimamente ligado aos campos de estágios e ao CI, indicando que a IESC enquanto tema transversal está presente. Por sua vez o CI está baseado na metodologia ativa de ensino, e apresenta inúmeros desafios e implicações, dos quais se sobressai o rompimento com o ensino tradicional.

Uma das primeiras aquisições do estudante que se insere no CI é a mudança de hábitos, o desenvolvimento de competências diferenciadas, o de aprender a trabalhar com o novo, com o outro e o senso de responsabilidade científica. Essas habilidades desenvolvidas no decorrer da graduação são respostas ao processo de aprender que, ao exercitar as múltiplas dependências, torna-o um sujeito autônomo. ${ }^{(11)}$

As atividades de ensino e aprendizagem propostas pelo currículo integrado em estudo promoveram a relação entre teoria e prática, a autonomia na busca pelo conhecimento, a possibilidade de atuação em diversos campos de estágios, a integração das disciplinas, a integração entre os alunos, professores, profissionais de saúde e indivíduos da comunidade, refletindo na integração ensinoserviço-comunidade.

No processo de ensino e aprendizagem é recomendável que se dê ao estudante a oportunidade para exercitar seu pensamento e explorar relações, que o pensamento deixe de ser instrumento de passividade, conformismo e submissão para tornarse um ato "libertador". ${ }^{(12)}$ Observamos que isto foi potencializado por meio do tema transversal IESC, ao integrar os centros formadores, os diversos serviços e esferas governamentais na relação direta ou indireta com a comunidade. Tal observação é convergente com a política pedagógica do CI em estudo, pois permite ao estudante superar questões relacionadas ao ensino tradicional, às disciplinas fragmentadas e divididas que o impedem de contextualizar.
Morin(5) critica o ensino por disciplinas, fragmentado e dividido, que acaba por dificultar a capacidade natural que o espírito tem de contextualizar o conhecimento. Esta capacidade deve ser estimulada e desenvolvida pelo ensino, possibilitando ao estudante ligar as partes ao todo e o todo às partes. ${ }^{(13)}$

A interdisciplinaridade tem o objetivo de desenvolver, em todas as áreas do conhecimento ligadas à prática de ensino, pesquisa e extensão na graduação e na pós-graduação, uma necessidade de organização curricular que articule os conhecimentos. $^{(14)}$

Nas discussões dos grupos focais a interdisciplinaridade foi apontada pelos estudantes como pertinente. Acreditamos que a interdisciplinaridade é uma ferramenta importante na compreensão da IESC, principalmente considerando que enquanto tema transversal esperase que ela perpasse as quatro séries articulando a formação profissional em enfermagem com os diversos níveis de atuação dos serviços com vistas à participação da comunidade nesta relação.

Esta situação expressa pode ser aproximada do operador dialógico proposto por Morin ${ }^{(15)}$, pois envolve juntar e entrelaçar coisas, que aparentemente estão separadas, porém que são complementares. Assim, a teoria e a prática, as diferentes disciplinas com suas áreas de conhecimento específicas, bem como a relação entre estudantes, professores, profissionais e comunidade devem ser entrelaçadas, complementando-se umas as outras. Apesar de em alguns momentos poderem apresentar significados e ou papéis antagônicos, podem ser trabalhadas de forma complementar. Acreditamos que somente assim, a real compreensão sobre a IESC poderá ser alcançada.

A relação entre professor e estudantes deve ser amigável a fim de propiciar o desenvolvimento do aluno, porém, é possível perceber os diversos obstáculos enfrentados nesta relação. O papel do professor como mediador e participe das relações interpessoais entre os estudantes, também é 
marcado por outro obstáculo para a compreensão, já que o professor deveria empreender esforços para que o conhecimento fosse alcançado pelo estudante, ao mínimo indicar ou aproximar o caminho a ser percorrido, em contraste com a realidade vivenciada, como pode ser observado nos discursos anteriormente apresentados. A situação gerada pela atitude docente leva a um modo de pensar, que aliado à incompreensão, pode reduzir a motivação do estudante e gerar conflitos éticos. A crença em verdades absolutas destrói a possibilidade de compreensão das verdades de outras pessoas. ${ }^{(15)}$

Outras falas retratam também dificuldades, mas não se limitam a elas, pois percebem pontos relevantes nessa interação, fazendo uso do artifício de reconstrução do conhecimento frente às dificuldades impostas. Morin ${ }^{15}$ diz que só assim será possível, ao homem, julgar seu próprio egocentrismo e, desse modo, não assumir a posição de juiz de todas as coisas.

No que se refere à integração entre cursos, foram mencionadas algumas dificuldades em relação à integração entre os cursos de medicina e enfermagem, que são mediados pelos docentes. Alguns estudantes percebem que esta tentativa de integração dificulta o aprendizado, enquanto outros conseguem perceber suas vantagens.

As discussões acerca das relações interpessoais foram ricas, sobretudo quando tratadas do ponto de vista dos estudantes de enfermagem em relação aos estudantes de medicina e desses em relação aos professores, houve relatos de inconformidades nas relações de poder e privilégios entre estudantes de medicina e enfermagem, ora mediada pela conduta docente, ora mediada pelos próprios estudantes, resultando em uma dicotomia entre os dois cursos, influenciando a aprendizagem significativa e a compreensão intelectual dos assuntos abordados.

As relações interpessoais têm um lugar significativo nos processos psicossociais e tratam da forma como as pessoas interagem nas relações umas com as outras. Toda relação interpessoal partilha certas propriedades que formam sua estrutura e qualidades afetivas; quando essas relações se situam em âmbito profissional adquirem implicações e características específicas. ${ }^{(3)}$ Para Morin, ${ }^{(5)}$ o "ruído" retrata justamente esta condição que interfere na transmissão da informação, criando o mal-entendido ou não entendido, gerando um sentimento de redução, como percebido nas falas.

\section{Avançando Para A Integração Ensino-Serviço}

As concepções sobre a integração entre ensino e serviço iniciaram no primeiro contato dos estudantes com os profissionais do serviço de saúde, sendo construídas ao longo do curso, ampliando o conhecimento por meio da troca de experiências, reforçando a importância da integração entre discentes e equipe de saúde.

O trabalho em saúde é compreendido como uma atividade humana realizada por um grupo de pessoas que a ela se dedica e, assim, reproduz uma existência humana. O trabalho é determinado por uma necessidade ou por uma carência. É também o meio de subsistência para a satisfação das necessidades materiais e não materiais, possibilitando a livre criação. $^{(16)}$

Sendo assim, o trabalho em saúde deve mobilizar conhecimentos em qualquer tempo ou situação em que se fizer necessário, assim como informações, e atitudes para aplicá-los, com capacidade de análise, em situações reais, individualmente e com a equipe, reunindo habilidades e sendo político-social. As ações das equipes devem reunir esforços que visem o alcance dos objetivos comuns e contemplar habilidades fundamentais como a técnica humana e conceitual, o que requer teorias científicas. ${ }^{(16-17)}$

Morin $^{15}$ defende que novos conhecimentos são construídos, por meio de sucessivas aproximações, de forma ativa e contextualizada. Portanto, as relações interpessoais consistem em processos que permitem uma mutualidade, ou seja, o convívio e as trocas humanas, sendo elas de cunho técnico, teórico 
ou de experiências cotidianas; estas propiciam o aprimoramento das pessoas. ${ }^{(18)}$

Ao abordar a integração ensino-serviço, os estudantes mencionaram o trabalho em equipe multiprofissional, identificando como integrantes o médico, enfermeiro, fisioterapeuta, técnico em enfermagem, psicólogo, nutricionista, serviço social e terapeuta, devendo realizar o trabalho em equipe de maneira integralizada, a fim de atender as necessidades de cada indivíduo. Esta percepção facilita a compreensão dos estudantes sobre a IESC, uma vez que o trabalho em equipe multiprofissional é indispensável para a assistência à saúde da comunidade.

Baseado nestes pressupostos e nos possíveis conflitos que possam surgir na equipe multiprofissional, a formação do enfermeiro deve visar o desenvolvimento de habilidades relacionais e de gerenciamento de conflitos. Assim, saber negociar depende de cada indivíduo, pois há fatores que podem influenciar, como cultura, crenças, valores, costumes, grau de conhecimento do problema, sentimentos, entre outros, contudo deve ser conduzido de forma amigável, independente do problema/conflito, o resultado da negociação deve ser satisfatório para ambas as partes. ${ }^{(19)}$

Morin também relata em sua obra que em determinadas situações e no uso do modo de pensar dialógico, é necessário trabalhar com posições opostas ou inconciliáveis sem tentar negá-las ou racionalizá-las, compreender estas situações e incorporar essa compreensão às nossas táticas, estratégias e práticas, é antes de tudo, uma demonstração de bom senso. ${ }^{(15)}$ Resta-nos cultivarmos esse bom senso no desenvolvimento da IESC na formação do enfermeiro.

Ao analisar o relacionamento interpessoal sob a ótica do princípio recursivo, pode-se inferir que este princípio esteve presente na IESC entre os estudantes, profissionais, docentes e indivíduos da comunidade, uma vez que ora atuavam como causas ora como produtores em um processo de troca e retroca durante todo o tempo. Ou seja, neste processo de ora ser causa, ora ser consequência, as dificuldades vivenciadas nos relacionamentos, por vezes, foram também as alavancas facilitadores para o desenvolvimento de novas habilidades e novas perspectivas.

A fim de propiciar a IESC, elementos como união, comunicação, participação, empatia, respeito, princípios e valores, e integralidade se tornam essenciais em todas as relações humanas, assim, o enfermeiro deve ser o profissional responsável por disseminar estes elementos entre sua equipe e comunidade, evitando possíveis conflitos e dificuldades.

\section{Integrando O Ensino E A Comunidade}

As concepções dos estudantes acerca da comunidade possibilitou perceber o ser humano como um ser biopsicossocial, que deve ser cuidado em todas as suas dimensões. Esta visão foi construída a partir da proposta pedagógica do curso, desenvolvendo-se por meio de bases teóricas e práticas.

Nesse estudo, observam-se relatos de estudantes das quatro séries acerca da humanização e da integralidade da assistência, destacando que a assistência e o cuidado prestado ao paciente devem ser de forma integral, percebendo o paciente como um todo, não tão somente em seus aspectos biológicos, mas um ser com outras perspectivas inerentes ao ser humano.

A integralidade surge como a capacidade dos profissionais de diferentes serviços de saúde interagir com os usuários, produzindo um território comum, que possibilite o diálogo entre eles. ${ }^{(20)} \mathrm{O}$ princípio hologramático busca a integração entre o todo e as partes, sendo este princípio aplicado pelos estudantes quando enxergam o paciente como um todo, considerando seus aspectos biopsicossociais, representado pelas partes. Quando o estudante consegue alcançar este nível de percepção do 
indivíduo, alcança o todo, realizando uma ação integral em saúde.

A contribuição da interdisciplinaridade para a Enfermagem advém não só para eliminar barreiras profissionais entre os temas que contribuem para o desenvolvimento de pesquisas, mas também provocam reflexões entre as pessoas que nela atuam, de modo a buscar alternativas para se conhecer mais e melhor o indivíduo sem esquecer as diversidades de relações da vida familiar, social, cultural, biológica, a doença e a saúde, entre outras, um modo de proceder intelectualmente, uma prática de trabalho cientifico, profissional e de construção coletiva. ${ }^{(21)}$

Assim como na integração entre ensino e serviço, a integração com a comunidade também necessita de empatia e respeito aos valores e princípios. Assim, a empatia foi exercitada pelos estudantes durante os estágios, no momento de atendimento à comunidade. $\mathrm{O}$ conceito de empatia possui várias vertentes, no entanto todas consideram a capacidade de compreender os sentimentos de outra pessoa e comunicá-la de tal experiência, sempre baseada nos pilares cognitivos, afetivos e comportamentais. ${ }^{(22)}$

Observa-se, portanto, que a IESC favorece a aproximação com a empatia. Já há alguns anos existem recomendações para a inclusão e o aprimoramento deste conteúdo na formação inicial e permanente de profissionais de saúde, uma vez que, a empatia proporciona tanto a satisfação dos pacientes, quanto a dos trabalhadores. ${ }^{(23)}$

O respeito é percebido pelos estudantes quando confrontados com as diferentes realidades oportunizadas pelas relações interpessoais com outros estudantes e profissionais, mas, sobretudo, na relação direta com a comunidade. Respeitar envolve ouvir o que o outro tem a dizer, buscando interpretar o que ouvimos, ter compaixão, ser tolerante, honesto, atencioso, é entender a necessidade do autoconhecimento para poder respeitar a si próprio e, então, respeitar o outro. ${ }^{(24)}$
Pode-se inferir que a IESC favorece a aquisição do respeito, pois segundo os relatos dos estudantes, o respeito é percebido nas relações interpessoais, e, deve ser incentivado sempre, pois é um mecanismo que regula e permeia as relações sociais do futuro profissional enfermeiro.

A IESC oportuniza ao estudante, segundo os relatos, que os valores e princípios estão ligados a visão de mundo, na qual percebemos e interpretamos o mundo e o eu no mundo, tanto para compreendêlo como para transformá-lo segundo a percepção de cada um acerca da realidade vivenciada. Fazer uso de valores e princípios para interagir com a realidade é uma excelente ferramenta qual dispõem um indivíduo, grupo social, uma comunidade e uma sociedade, para voltar ao passado, compreender seu presente e fazer previsões para construir seu futuro. Quando compreendemos que a realidade é o que o nosso método de observação nos permite perceber, e, passamos a reconhecer que nossa visão de mundo formata nossos modelos mentais, através dos quais observamos, sistematizamos, interpretamos e aportamos significado às nossas próprias experiências no mundo. ${ }^{(25)}$

Compreendendo A Integração Ensino-ServiçoComunidade

A integração entre ensino, serviço e comunidade foi percebida e mencionada no contexto da atenção primária, secundária e terciária, enfatizando a importância da interdisciplinaridade no cotidiano do enfermeiro, proporcionando um cuidado mais individualizado e centrado nas necessidades do paciente e comunidade. ${ }^{(26)}$

Ao relembrar o conceito da IESC é improvável não associá-lo com a comunicação, pois se refere diretamente da relação dos três elos: ensino, serviço e a comunidade, interligados pela integração. Neste sentido, as falas indicam que nas experiências de aprendizado o estudante percebe a comunicação como relevante, embora talvez ele não consiga vislumbrá-la de forma madura. 
De acordo com autores, a comunicação é como um ato de compreender e compartilhar informações enviadas e recebidas, as mensagens são as formas de intercâmbios entre os envolvidos. Esta troca influenciará no comportamento das pessoas. ${ }^{(27)}$

Frente aos relatos trazidos, acredita-se que a comunicação na IESC é uma importante ferramenta na formação do estudante, e, corroborando com essa ideia, Oliveira e Soares $^{(27)}$ afirmam que a comunicação envolve a importância vital que o futuro enfermeiro assimile sempre, se o que foi entendido corresponde ao que o outro está expressando, analisando as informações e os dados disponíveis, esclarecendo suas percepções, tentando compreender o outro.

As experiências relacionadas à IESC vivenciadas pelos estudantes apontam a compreensão dos mesmos acerca da complexidade do tema em questão, bem como de sua importância e desenvolvimento durante a graduação. Foi possível analisar nas falas, que ao se depararem com situações reais e problemas de saúde da comunidade, os estudantes buscaram a equipe multiprofissional a fim de solucionar os desafios encontrados, integrando seus conhecimentos teóricos, a experiência dos profissionais do serviço de saúde e a prestação de assistência à comunidade.

O operador hologramático de Morin(15) diz que as partes estão no todo, mas o todo também está nas partes. Isto pode ser observado em várias atividades desenvolvidas em grupo para discutir determinado assunto ou problema, por meio das interações que se estabeleciam entre eles culminando em ideias novas, que antes não haviam ocorrido aos participantes. Observa-se que a sabedoria de um grupo é maior do que a simples soma da sabedoria de um de seus componentes.

O princípio dialógico também se faz presente nesta análise, uma vez que diferentes profissões da área da saúde possuem atuações e olhares diferentes, ao mesmo tempo são complementares umas às outras, atuando de maneira conjunta e complementar a fim de alcançar um objetivo comum.
Apoiado em Morin $^{(5)}$ pode-se afirmar que o estudante ao comparar e interligar as necessidades de saúde do indivíduo nos diferentes serviços faz uma aproximação com o pensamento complexo, já que este se refere ao que é profundo e interligado. O pensamento simples, segundo o autor, não é necessariamente verdadeiro, dado o processo de simplificação e a tentativa de se apropriar da realidade. Enquanto isso, o pensamento complexo sustenta-se na ordem, clareza e exatidão no conhecimento, ou seja, aproxima-se da realidade. O grande desafio do pensamento complexo, para Morin, é poder estabelecer uma articulação entre os mais diversos campos de pesquisas e temas.

Os desafios na formação e no desenvolvimento dos trabalhadores de saúde são não fragmentar a assistência, não perder o conceito de atenção integral, realizar trabalhos em conjunto com os setores e aceitar que há incertezas nas definições dos papéis dos profissionais, haja vista que existe alternância de práticas e de saberes, principalmente no contexto das equipes. Assim, a recursividade de faz presente neste contexto, devendo os profissionais e estudantes se esforçar para alcançar o bem comum. ${ }^{(28)}$

$\mathrm{Na}$ perspectiva de Morin, ${ }^{(15)}$ utilizando o operador hologramático, para alcançar o todo na IESC, necessitamos integrar as partes e, podemse considerar os elementos essenciais descritos pelos estudantes compõem partes da IESC. Desta forma, utilizando união, participação, comunicação, empatia, respeito, princípios e valores, e integralidade para desenvolver a IESC, estamos também nos aproximando do que ela realmente é e representa. Pois, não só as partes estão no todo, como o todo também está nas partes. Assim, o estudante percebe os espaços nos quais o indivíduo, a família, a comunidade, o ensino, a integração, o serviço e a sociedade interagem entre si como um todo e como partes, permeados pela integralidade e humanização. 


\section{Conclusões}

As concepções acerca da IESC atribuídas pelos estudantes permitiram analisar que os estudantes constroem ao longo do curso suas percepções sobre o ensino, o serviço e a comunidade, muitas vezes de maneira parcial e fragmentada, porém alcançam a compreensão como um todo ao aprofundar a discussão sobre o tema.

Esta integração entre diferentes instituições, profissionais e indivíduos é possibilitada pela problematização do CI e a oportunidade do estudante aplicar o pensamento crítico dentro de seu campo de prática, junto à equipe multiprofissional, sendo capaz de transformar as condições de sua existência em relação aos diferentes problemas vivenciados perante a comunidade, tornando-se transformadores de realidades.

As relações interpessoais ganharam destaque neste estudo, sendo percebidas entre estudantes de diferentes cursos, professores e estudantes e estudantes e profissionais/equipe de saúde. É preciso enfatizar que as relações interpessoais têm um significado especial nas relações psicossociais, marcadas pelas propriedades afetivas e especificas da profissão de Enfermagem. Nas discussões trazidas pelos estudantes acerca desse assunto, reitera-se que as relações interpessoais advindas da IESC são marcadas pela necessidade de comunicação, participação, cooperação, empatia, respeito, aprendizado e dos valores e princípios. A IESC relacionada às relações interpessoais nesse estudo as destacou.

A pretensão deste estudo não foi apenas ressaltar a discussão da IESC no CI do curso de Enfermagem em estudo, mas apresentar esse tema transversal a outras instituições de ensino, aos enfermeiros dos serviços, incluindo a comunidade como partícipe. Conclui-se que essa pesquisa não se esgota aqui, pelo contrário, que ela seja capaz de despertar outros caminhos para outras discussões da IESC na formação do enfermeiro e de outros profissionais de saúde.

\section{Referências}

1 Costa RKS, Miranda FAN. Opinião do graduando de enfermagem sobre a formação do enfermeiro para o SUS: uma análise da FAEN/UERN. Esc Anna Nery Rev Enferm. [Internet]. 2010 [citado 2018 maio 20]; 14(1):39-47. Disponível em: http://www.scielo.br/ pdf/ean/v14n1/v14n1a07.pdf

2 Scherer ZAP, Scherer EA, Carvalho AMP. Reflexões sobre o ensino da enfermagem e os primeiros contatos do aluno com a profissão. Rev Latino-Am Enfermagem [Internet]. 2006 [citado 2018 maio 20]; 14(2): 285-91. Disponível em: http://www.scielo.br/pdf/rlae/v14n2/ v14n2a20.pdf

3 Villela SC, Carvalho AMP, Pedrão LJ. Relação interpessoal como forma de cuidado em enfermagem nas estratégias de saúde da família. Rev Enferm UERJ [Internet]. 2006 [citado 2018 maio 20]; 22(1): 96102. Disponível em: http://www.facenf.uerj.br/v22n1/ v22n1a15.pdf

4 Guariente MHDM, Kikuchi EM, Carvalho WO, Vannuchi MTO, Dessunti EM, Gastaldi AB. Seivas do currículo integrado de enfermagem. Em: Kikuchi EM, Guariente MHDM (org.). Currículo integrado: a experiência do curso de enfermagem da Universidade Estadual de Londrina. Londrina: UEL; 2014. p. 93-128

5 Morin E. Introdução ao pensamento complexo. Porto Alegre: Sulina; 2015.

6 Universidade Estadual de Londrina. Projeto políticopedagógico do curso de enfermagem. Londrina: UEL; 2015.

7 Garanhani ML, Vannuchi MTO, Pinto AC, Simões TR, Guariente MHDM. Integrated nursing curriculum in Brazil: A 13-year experience. Creative Education [Internet]. 2013 [citado 2018 maio 20]; 4(12): 66-74. Doi: $10.4236 /$ ce.2013.412A2010

8 Dessunti EM, Guariente MEM, Kikuchi EM, Tacla MTGM, Carvalho WO, Nóbrega GMA. Contextualização do currículo integrado do curso de Enfermagem da Universidade Estadual de Londrina. Em: Kikuchi EM, Guariente MHDM (Org.). Currículo integrado: a experiência do curso de enfermagem da Universidade Estadual de Londrina. Londrina: UEL; 2014. p. 17-32.

9 Bardin L. Análise de conteúdo. Lisboa: Edições 70; 2011.

10 Morin E. O método 5: a humanidade da humanidade. Porto Alegre: Sulina; 2012.

11 Floter FS. Aprendizagem para o trabalho em equipe: reflexões na perspectiva do estudante de enfermagem 
e do Pensamento Complexo [tese]. Londrina(PR): Universidade Estadual de Londrina; 2015.

12 Santos J, Meira KC. Operações de pensamento e estratégias de ensino: relações e complexidade como uma alternativa para tomada de decisão na dinâmica dos processos de ensino-aprendizagem. Rev Eletrônica Gest e Saúde. [Internet]. 2015. [citado 2018 maio 20]; 6(3): 2024-38. Disponível em: http://periodicos.unb.br/ojs32/index.php/rgs/article/ view/3062/2755

13 Morin E, Almeida MC, Carvalho EA. Educação e complexidade: os sete saberes e outros ensaios. São Paulo: Cortez; 2009.

14 Galvão SFOL, Fazenda ICA. A parceria na interdisciplinaridade: formação de uma nova consciência coletiva-estudos a partir das vivências em ensino superior. Interdisciplinaridade. [Internet]. 2014. [citado 2018 maio 20]; 1(5): 42-60. Disponível em: https://revistas.pucsp.br/index.php/ interdisciplinaridade/article/view/20747/15292

15 Morin E. Complexidade e transdisciplinaridade: a reforma da universidade e o ensino fundamental. Tradução Edgar de Assis Carvalho. Natal: EDUFRN; 2000.

16 Martins MG. Revisão integrativa sobre o Conceito de Trabalho em Equipe na Perspectiva da Integralidade na Atenção Primária à Saúde [dissertação]. Alfenas (MG): Universidade Federal de Alfenas; 2013.

17 Mendes KDS, Silveira RCCP, Galvão CM. Revisão Integrativa: método de pesquisa para a incorporação de evidências na saúde na enfermagem. Texto Contexto- Enferm [Internet]. 2008 [citado 2018 maio 20]; 17(4): 758-64. Disponível em: http://www. scielo.br/pdf/tce/v17n4/18.pdf

18 Fernandes HN, Thofehrn MB, Porto AR, Amestoy SC, Jacondino MB, Soares, MR. Relacionamento interpessoal no trabalho da equipe multiprofissional de uma unidade de saúde da família. Rev Pesqui Cuid Fundam [Internet]. 2015. [citado 2018 maio 20]; 7(1): 1915-26. Disponível em: http://www.redalyc.org/ pdf/5057/505750945016.pdf

19 Melo ACB. Conflitos na equipe de trabalho da unidade de pronto socorro de um hospital particular e sua influência na assistência ao paciente. Recife; 2012 .

20 Oliveira CO, Cutolo LRA. Humanização como expressão de integralidade. Mundo Saúde. [Internet]. 2015 [citado 2018 maio 20]; 36(6): 502-6. Disponível em: http://bvsms.saude.gov.br/bvs/artigos/mundo saude/humanizacao_expressao_integralidade.pdf
21 Camacho ACLF. A gerontologia e a interdisciplinaridade: aspectos relevantes para a enfermagem. Rev Latino-Am Enferm. [Internet]. 2002. [citado 2018 maio 20]; 10(2): 229-33. Disponível em: http:/www.scielo.br/pdf/rlae/ v10n2/10519.pdf

22 Savieto RM, Leão ER. Assistência em Enfermagem e Jean Watson: Uma reflexão sobre a empatia. Esc Anna Nery [Internet]. 2016 [citado 2018 maio 20]; 20(1): 198-202. Disponível em: http://www.scielo.br/ pdf/ean/v20n1/1414-8145-ean-20-01-0198.pdf

23 Formiga NS. Os estudos sobre empatia: reflexões sobre um construto psicológico em diversas áreas científicas. [Internet]. 2012 [citado 2018 maio 15]. Disponível em: http:// www.psicologia.pt/artigos/ textos/A0639.pdf

24 Tôrres JTM. Teoria da complexidade: uma nova visão de mundo para a estratégia. Rev Integra Educativa. [Internet]. 2015 [citado 2018 maio 20]; 2(2): 189202. Disponível em: http://www.scielo.org.bo/pdf/ rieiii/v2n2/n02a08.pdf

25 Oliveira CO, Cutolo LRA. Humanização como expressão de integralidade. Mundo Saúde. [Internet]. 2015 [citado 2018 maio 20]; 36(6): 502-6. Disponível em: http://bvsms.saude.gov.br/bvs/artigos/mundo_ saude/humanizacao_expressao_integralidade.pdf

26 Ministério da Saúde (BR). Portaria $\mathrm{n}^{\circ} 2.488$, de 21 de outubro de 2011. Aprova a Política Nacional de Atenção Básica, estabelecendo a revisão de diretrizes e normas para a organização da Atenção Básica, para a Estratégia Saúde da Família (ESF) e o Programa de Agentes Comunitários de Saúde (PACS). Diário Oficial da União 24 out 2011.

27 Oliveira AM, Soares E. A Comunicação como Importante Ferramenta nas Orientações em uma Unidade de Hemodiálise: um estudo reflexivo. Saúde \& Transformação Social [Internet]. 2015 [citado 2018 maio 20]; 5(3): 118-23. Disponível em: http://incubadora.periodicos.ufsc.br/index.php/ saudeetransformacao/article/view/2279/4012

28 Ceccim RB, Ferla AA. Residência integrada em saúde: uma resposta da formação e desenvolvimento profissional para a montagem do projeto de integralidade da atenção à saúde. Em: Pinheiro R, Mattos RA. (Org.) Construções da integralidade: cotidiano, saberes e práticas em saúde. Rio de Janeiro: CEPESC-IMS/UERJ-ABRASCO; 2010.

Recebido em: 20 jun. 2018 Aceito em: 16 jan. 2019 
